\title{
Effect of Fucoidan of Brown Seaweeds on the Immuno-haematological Change and the Disease Resistance against Aeromonas hydrophila in Tilapia Oreochromis mossambicus
}

\author{
V. Rani", P. Jawahar, R. Jeyashakila and A. Srinivasan \\ Fisheries College and Research Institute, Tamil Nadu Dr. J. Jayalalithaa Fisheries \\ University, Thoothukudi - 8, Tamil Nadu, India \\ *Corresponding author
}

\begin{abstract}
A B S T R A C T
Ke y w ords

Brown seaweeds, fucoidan, Hematological changes, Innate immunity, Oreochromis mossambicus, Aeromonas hydrophila

Article Info

Accepted:

10 July 2020 Available Online: 10 August 2020

An experiment was conducted to study the influence of dietary fucoidan from brown seaweeds viz., Padina tetrastromatica and Sargassum oligocystum on the innate immunity and disease resistance of fish Oreochromis mossambicus. Fucoidan was supplemented with fish feed at different concentrations such as 0.1 , 0.2 and $0.3 \%$ to observe hematological changes and non-specific immunological properties for a period of 60 days. The results indicated that fucoidan supplemented diet had no significant effect on hematological changes whereas, the lysozyme activity was significantly increased in the fishes fed with fucoidan of $P$. tetrastromatica $\left(4012 \pm 2198 \mathrm{IU} \mathrm{ml}^{-1}\right)$ on $30^{\text {th }}$ day and $S$. oligocystum $(2412 \pm 221$ $\mathrm{IU} \mathrm{m} \mathrm{m}^{-1}$ ) on $15^{\text {th }}$ day at $0.2 \%$ and $0.3 \%$ concentration, respectively. NBT activity was found to be highest at $15^{\text {th }}, 30^{\text {th }}$ and $45^{\text {th }}$ days in fishes fed with $0.1,0.2$ and $0.3 \%$ of fucoidan derived from $P$. tetrastromatica. The results stated that the fucoidan derived from $S$. oligocystum has relatively lower lysozyme and NBT activity than from $P$. tetrastromatica but higher than the control. The fish O.mossambicus challenged with A. hydrophila, feeding offucoidan extracted from the seaweeds invariably increased the survival upto $75 \%, 80 \%$ at 0.2 and $0.3 \%$ and $65,70 \%$ respectively than the control.

\section{Introduction}

The native seaweeds are dominantly abundant along the coast of Gulf of Mannar but are not effectively exploited either for commercial application or human health or agriculture and aquaculture purposes. Seaweed products like k-carrageenan and liquid fertilizer have received greater demand in the market, after

the culture practice of exotic red seaweed, Kappaphycus alverazii has witnessed a positive sign as through implementation by self-help groups rather than corporate farms (Mantri et al., 2017). Among the three major groups of seaweeds, brown seaweeds contain more biological properties compared to red and green seaweeds (Seafood Plus, 2004) and specifically used to produce polysaccharides
\end{abstract}


like alginates, laminarians and fucoidan (Lee et al., 2008). The Gulf of Mannar Biosphere Reserve Trust (GoMBRT), Ramanathapuram also permits the utilization of brown seaweeds available along the coast of Gulf of mannar throughout the year. The biodiversity of brown seaweeds and their seasonal abundance along the Gulf of mannar were assessed by few authors (Rao 1972; Kannan and Krishnamurthy 1978; Oza and Zaidi 2000; Rani et al., 2015).

Fucoidan is a sulfated polysaccharide found in the cell walls of brown seaweeds. In recent years, researchers have identified the biological properties of Indian seaweeds for various properties such as antibacterial and antiviral against various clinical and fish pathogens (Radhika et al., 2012; Maheswaran et al., 2013), anti-oxidative (Chattopathyay et $a l ., 2010)$ and immunomodulatory properties on shrimp (Immanuel et al., 2012). There are reports utilizing the herbal immunostimulants derived from terrestrial plants for aquaculture purposes (Sakai 1999). Fucoidan from brown seaweeds as an immunostimulant has received much attention recently and several studies have reported on their immunomodulatory properties (Itoh 1993; Choi et al., 2005; Yeh et al., 2006; Hwang et al., 2010; Yang 2014).

Aeromonas hydrophila is one of the most important bacterial pathogens in freshwater as well as brackish water aquaculture systems (Karunasagar and Rosalind 1991). It causes severe detrimental effects in carp farming, which is widely practiced in India. Tilapia has become the second most popular fish in India and its farming is flourishing nowadays. It has entered the list of best-selling fish species like shrimp and salmon. There is no literature available on the effect of fucoidan on the immuno-hematological changes in tilapia cultured in controlled condition. Hence, the present study was undertaken to analyze the effect of fucoidan as dietary supplements in the tilapia, Oreochromis mossambicus by observing the hematological parameters to assess their immune response by examining disease resistance against pathogenic bacteria, A. hydrophila in the experimental culture condition.

\section{Materials and Methods}

\section{Brown seaweeds}

Two species of brown seaweeds viz., Sargassum oligocystum and Padina tetrastromatica were collected from two locations viz., Valinokkam $\left(09^{\circ} 13.684^{\prime} \mathrm{N}\right.$, $\left.078^{\circ} 47.194^{\prime} \mathrm{E}\right)$ and Hare Island (08 047.254' $\mathrm{N}, 078^{\circ} 11.884^{\prime}$ E) of Gulf of Mannar during the year 2014. They were used to extract the fucoidan by the standard protocol described by Yang et al., 2008 with slight modification. The shade dried pulverized seaweed $(20 \mathrm{~g}$ )was treated with $1 \mathrm{~L}$ of $85 \%$ ethanol with constant stirring for $12 \mathrm{~h}$ at room temperature in order to remove proteins and pigments. The ethanol treated seaweed was washed with acetone, centrifuged at $10000 \times \mathrm{g}$ for $10 \mathrm{~min}$. and then dried at room temperature. The dried biomass $(5 \mathrm{~g})$ was extracted with $100 \mathrm{ml}$ of distilled water at $65^{\circ} \mathrm{C}$ with continuous stirring for $1 \mathrm{~h}$ twice, and the extracts were combined. The combined extract was centrifuged at $10000 \times \mathrm{g}$ for $20 \mathrm{~min}$. and the supernatant was treated with $1 \%$ of $\mathrm{CaCl}_{2}$ and kept at $4{ }^{\circ} \mathrm{C}$ for overnight to precipitate the alginic acid after centrifugation at $10000 \times \mathrm{g}$ for $20 \mathrm{~min}$. and the supernatant was collected. Ethanol was added into the supernatant to obtain a final ethanol concentration of $30 \%$, and the solution was placed at $4{ }^{\circ} \mathrm{C}$ for $4 \mathrm{~h}$ in a chill cabinet. Again, the solution was centrifuged at $10000 \times \mathrm{g}$ for $20 \mathrm{~min}$. to remove the remaining impurities as residue. Finally, ethanol was added into the supernatant to obtain a final ethanol concentration of $70 \%$, and then placed at $4^{\circ} \mathrm{C}$ overnight to precipitate out the intact fucoidan. After 
centrifugation at $10000 \times \mathrm{g}$ for $15 \mathrm{~min}$, the residue fucoidan was washed with ethanol and acetone, and again dried at room temperature. The yield was calculated based on the following formula:

$$
\text { Yield }(\%)=\frac{\text { Weight of the obtained fucoidan }(g) \times 100}{\text { Weight of the dried biomass }(\mathrm{g})}
$$

\section{Preparation of pellet feed supplemented with fucoidan}

Fucoidan extracted from two brown seaweeds were individually used for the preparation of pellet feed. Three types of pellet feed containing fucoidan were prepared following the procedure described by Yeh et al., 2008. The basal feed procured from commercial feed company (CP Aquaculture Feed India Ltd) without fucoidan served as the control feed.

The fucoidan was added individually to the basal feed at different concentrations viz., 0.1, 0.2 and $0.3 \%$ of the total weight to obtain test feed. All the ingredients were ground in a mixer grinder and then tapioca powder $(3 \%)$ and warm water as required were added to form the dough. The dough was pelletized using a laboratory model pelletizer (RKL 120 ) having $1 \mathrm{~mm}$ diameter and dried in a hot air oven set at $40^{\circ} \mathrm{C}$ overnight. The dried pellet feeds were stored in plastic containers at room temperature until use.

\section{Experimental system}

Tilapia (Oreochromis mossambicus) collected from the natural system of Pazhayakayal estuary near Thoothukudi was first acclimated in tap water for one month before the start of the experiments. Tilapia of both sexes weighing an average size of $12.5 \pm 0.5 \mathrm{~cm}$ in length and $28.5 \pm 0.5 \mathrm{~g}$ in weight were selected from the acclimatized stock and transferred into individual experimental tanks.
The experiment was carried out in circular cement tanks of $0.75 \mathrm{~m}$ diameter and containing $500 \mathrm{~L}$ of freshwater to stock 30 animals per tank. There were 12 tanks for three test feed and control feed trials in triplicate. The tilapia in control tank was fed with pellet feed without fucoidan. Mild aeration was provided continuously in order to maintain the optimal oxygen level. An ad libitum feeding regime was followed in all tanks and $25 \%$ water was exchanged daily during the experimental period of 60 days.

\section{Collection of blood samples}

Tilapia were selected randomly from each tanks after anaesthetizing them with MS-222 added at the rate of $100 \mathrm{mg} / \mathrm{L}$ to drawn blood for hematological analysis. Approximately, $0.05 \mathrm{ml}$ of blood was collected from the dorsal aorta using 20-gauge needle from the selected fish from either the right or left side on the $0^{\text {th }}, 15^{\text {th }}, 30^{\text {th }}, 45^{\text {th }}$ and $60^{\text {th }}$ day of the experimental period. The temperature was maintained at $4^{0} \mathrm{C}$ by placing the samples in refrigerator to allow complete healing of the withdrawal site. Heparin sodium (1\%) was used as an anticoagulant. The first half of the collected blood was heparinized and used for the hematological and NBT activity (Nitro Blue Tetrazolium-NBT assay) and the second half of blood was not heparinized and the serum was used to assess the lysozyme activity.

\section{Hematological parameters}

Hematological parameters viz., haemoglobin, RBC and WBC were determined in heparinized blood within $2 \mathrm{~h}$ after sampling. The blood was diluted with appropriate diluting fluids to determine the $\mathrm{RBC}$ and WBC counts using improved Neubauer haemocytometer and calculation was done as per the procedure of Barcellos et al., 2004. 


\section{Haemoglobin content}

Haemoglobin content was estimated by haemocytometer with permanent coloured glass comparison standards (Superior Marine Field, Germany) and the value was expressed as gram per deciliter (g/dl).

\section{Red Blood Cells (RBC) count}

The heparinized blood was diluted with equal volume of RBC (Hayemis) diluting fluid solution and RBC count was determined manually with haemocytometer. The total number of RBC was counted in the five RBC squares of the central large square of the chamber in duplicate. The average values having less than $15 \%$ were taken and multiplied by 10,000 to calculate the number of RBCs per microliter.

\section{White Blood Cells (WBC) Count}

The heparinized blood was diluted 100 times with WBC diluting fluid (Hi-Media )and the count was determined in haemocytometer. The WBC count from the four large squares of the chamber was counted in duplicate. The average counts having less than $15 \%$ difference were taken and multiplied by dilution factor to calculate the number of WBC per microliter.

\section{Non-specific immune response studies}

\section{NBT reduction assay}

Nitrobluetetrazolium (NBT) assay was performed following the method described by Stasiak and Baumann 1996. The heparinized blood was placed in Eppendorf tubes and the puffy coat was separated by centrifuging at $500 \mathrm{xg}$ at $4^{0} \mathrm{C}$ for $10 \mathrm{~min}$. Exactly, $50 \mu \mathrm{l}$ of the puffy coat was placed into each well of a 96 wells of ' $U$ ' bottomed microliter plates (Tarson, India) and incubated at $37^{\circ} \mathrm{C}$ for $1 \mathrm{~h}$ to facilitate adhesion of cells. The supernatant was removed and $50 \mu \mathrm{l}$ of $0.3 \%$ NBT solution was added. After incubation at $37^{\circ} \mathrm{C}$ for $1 \mathrm{~h}$, NBT solution was removed. The cells were then fixed with $100 \%$ methanol, washed thrice with $70 \%$ methanol and air-dried. Then, $60 \mu \mathrm{l}$ of $2 \mathrm{~N}$ potassium hydroxide and $70 \mu \mathrm{l}$ diethyl sulphoxide (DMSO) were added into each well to dissolve the formazan blue precipitate. The turquoise-blue colored solution was then read in ELISA reader (BioTek) at $655 \mathrm{~nm}$.

\section{Lysozyme activity}

Lysozyme activity was measured by adapting the turbidimetric method described by Parry et al., 1965 with slight modification. Serum $(50 \mu 1)$ was placed in triplicate in a 96 well plate with $50 \mu \mathrm{l}$ phosphate buffered saline (PBS), $\mathrm{pH}$ 5.8. After mixing, the serum was serially diluted from one well to another. Finally, $50 \mu \mathrm{l}$ of mixer was discarded in the last well. To each well, $125 \mu \mathrm{l}$ of Micrococcus luteus (MTCC No:106) suspension (Aliquots of $15 \mathrm{mg}$ culture in $20 \mathrm{ml}$ of PSB yields $0.075 \%$ solution of M.luteus) was added $(100 \mathrm{mg} / \mathrm{mlin}$ phosphate buffer). The reduction in the absorbance at $450 \mathrm{~nm}$ was measured from 0 to $15 \mathrm{~min}$ at room temperature in an ELISA reader. The lysozyme activity was converted to lysozyme concentration using hen egg white lysozyme (Sigma, USA) as standard.

\section{Challenge studies with Aeromonas hydrophila}

\section{Preparation of culture suspension}

A. hydrophila (MTCC No.1739) was grown in Mueller Hinton nutrient broth (Hi Media) by placing in shaking water bath for $12 \mathrm{~h}$ at $20^{\circ} \mathrm{C}$ and centrifuged at $9,000 \mathrm{xg}$ for $20 \mathrm{~min}$ at $4^{\circ} \mathrm{C}$. The supernatant was discarded and the bacterial pellet was washed thrice with PBS 
( $\mathrm{pH}$ 7.2) and adjusted by dilution to get a concentration of $2.5 \times 10^{6} \mathrm{cfu} / \mathrm{ml}$ using Neubauerhemocytometer

\section{Infectivity study}

In order to determine the infectivity of $A$. hydrophila, 18 numbers of tilapia of both sexes $(30 \pm 1.5 \mathrm{~g})$ were chosen for testing six concentrations of $A$. hydrophila in triplicate was injected intramuscularly. About $100 \mu$ of A. hydrophila suspension of each concentration viz., $10^{5}$ to $10^{10} \mathrm{cfu} / \mathrm{ml}$ to induce septicemia in tilapia individually. At a concentration of $10^{6} \mathrm{cfu} / \mathrm{ml}$ of $A$. hydrophila, the mortality recorded as $50-60 \%$, while at $10^{8} \mathrm{cfu} / \mathrm{ml}$, the mortality was $90 \%$ after an incubation period of 10 days. Hence, $10^{6} \mathrm{cfu} / \mathrm{ml}$ was chosen further to ensure $50 \%$ survival.

\section{Challenge experiment set up}

In the previous experimental set up, upon completion of 60 days of feeding experiment, tilapia were challenged with intramuscular injection of $100 \mu \mathrm{l}$ of $12 \mathrm{~h}$ grown culture of the virulent $A$. hydrophila of having concentration of $2.5 \pm 0.3 \times 10^{6} \mathrm{cfu} / \mathrm{ml}$. Total plate count was determined by hemocytometer and the total viable bacterial count was confirmed by spread plate method. Simultaneously, a negative control group was also maintained. Mortality was observed daily up to 15 days and Relative Percentage Survival (RPS) was calculated following the method of Amend 1981 given in table. 6

\section{Results and Discussion}

In the present study, the biological parameters viz., temperature, $\mathrm{pH}, \mathrm{DO}$, ammonia, nitrite, nitrate, phosphate, alkalinity and hardness were analysed by the standard APHA (1995) method and the results are indicated in Table.1. The water in the tanks had pH (7.03 to 7.25$)$, temperature $\left(27.5\right.$ to $\left.28.3^{\circ} \mathrm{C}\right)$, dissolved oxygen $(5.52$ to $6.12 \mathrm{ml} / \mathrm{L})$, hardness (135.17 to $\left.143.7 \mathrm{CaCO}_{3}\right)$, alkalinity (147.5 to $155.5 \mathrm{mg} / \mathrm{L})$; with nutrients nitrite (15.25 to $18.43 \mu$ g.at. $\left.\mathrm{NO}_{2} \mathrm{~N} / \mathrm{L}\right)$, nitrate $(0.75$ to $0.92 \mu$ g.at. $\left.\mathrm{NO}_{3} . \mathrm{N} / \mathrm{L}\right)$, ammonia (0.058 to $0.093 \mu$ g.at. $\mathrm{NH}_{3} . \mathrm{N} / \mathrm{L}$ ) and phosphate (25.59 to $36.11 \mu$ g.at. $\left.\mathrm{PO}_{4} \cdot \mathrm{P} / \mathrm{L}\right)$. Nutrients were high in fucoidan incorporated diet fed tanks. Alkalinity was also more, but hardness was quite low. Temperature and $\mathrm{pH}$ were slightly high while dissolved oxygen level was quite low and the reason was not clear.

The results of the hematological parameters viz., hemoglobin, WBC and RBC examined for the tilapia fed with fucoidan incorporated diet and control are given in Table 2, 3 and 4 respectively. However, over the increase in the culture duration, the haemoglobin content in tilapia increased by approximately $0.5 \mathrm{~g} / \mathrm{dl}$ on the $60^{\text {th }}$ day irrespective of the variation in the diet. Similarly, the WBC count did not show much variation in tilapia fed with up to $0.2 \%$ fucoidan incorporated diet, but in $0.3 \%$ fucoidan incorporated diet, the WBC counts in tilapia was significantly high, irrespective of the type of seaweeds on $30^{\text {th }}$ day. Beyond 30 days the increase in WBC count was not substantial and had reduced in fucoidan fed tilapia. On the other hand, the RBC counts did not change significantly during the experimental period in tilapia fed with control and the test diets. Incorporation of fucoidan had not increased the RBC counts in the tilapia during the culture period.

In the present investigation, tilapia fed with fucoidan incorporated diet, the NBT reduction increased with increasing concentration of fucoidan obtained from $P$. tetrastromatica and S. oligocystum after 15 days. The effect continued with fucoidan of S.oligocystum while the effect was more pronounced with fucoidan of $P$. tetrastromatica on $30^{\text {th }}$ day. Beyond this duration, there was proportionate 
loss in NBT reduction in tilapia fed with fucoidan incorporated diet; with the loss being more in S. oligocystum fucoidan. On the $60^{\text {th }}$ day, the immune enhancement by fucoidan was totally lost in tilapia fed with S.oligocystum fucoidan; as the NBT reduction was on par with control diet. In $P$. tetrastromatica fucoidan fed tilapia, the effect was slightly high.

The lysozyme activity of control and experimental group fishes fed with fucoidan from $P$. tetrastromatica showed significant variation (Fig.3). In the present study, the maximum serum lysozyme activity was observed on the $30^{\text {th }}$ day with the tilapia fed with fucoidan of $0.2 \%$ incorporated diet (4012 $\left.\pm 2198 \mathrm{IU} \mathrm{ml} \mathrm{l}^{-1}\right)$, followed by $0.3 \%$ fucoidan $\left(3876 \pm 192 \mathrm{IU} \mathrm{ml}^{-1}\right)$ on the $15^{\text {th }}$ day. Thereafter the activity was decreased in all the treatments as the experiment prolonged.Similar results were observed for the fishes fed with fucoidan extracted from $S$. oligocystum(Fig 4).But the maximum activity was $2412 \pm 221 \mathrm{IU} \mathrm{ml}^{-1}$ in tilapia fed with fucoidan at $0.3 \%$ incorporated diet on the $15^{\text {th }}$ day.

In the fish challenge experiments, the relative percentage of survival was higher in tilapia fed with fucoidan from $P$. tetrastromatica at $0.2 \%$ and $0.3 \%$ concentrations (Table 5) and $0.3 \%$ fucoidan from S. oligocystum (Table 6). The results revealed that fucoidan from P.tetrastromatica can enhance the immunity better than fucoidan of $S$. oligocystum in tilapia. Also, the immunity enhancement by fucoidan was maximum up to 60 days of culture and latter slowly dropped and diminished beyond 60 days of culture; P.tetrastromatica fucoidan concentration of $0.2 \%$ with was found to provide a sustainable immunity till the end of the experimental period than other concentrations.

Table.1 Biological parameters monitored in experimental tanks

\begin{tabular}{|c|c|c|c|c|c|}
\hline $\begin{array}{l}\text { S. } \\
\text { No. }\end{array}$ & Parameters & Control & $\begin{array}{l}\text { Fucoidan } \\
\text { supplemented } \\
\text { with } 0.1 \%\end{array}$ & $\begin{array}{l}\text { Fucoidan } \\
\text { supplemented } \\
\text { with } 0.2 \%\end{array}$ & $\begin{array}{c}\text { Fucoidan } \\
\text { supplemented } \\
\text { with } 0.3 \%\end{array}$ \\
\hline 1. & $\mathrm{pH}$ & $7.03^{\mathrm{a}} \pm 0.07$ & $7.19^{b} \pm 0.03$ & $7.23^{\mathrm{b}} \pm 0.04$ & $7.25^{\mathrm{b}} \pm 0.04$ \\
\hline 2. & Temperature $\left({ }^{0} \mathrm{C}\right)$ & $27.5 \pm 0.29$ & $28.3 \pm 0.17$ & $27.7 \pm 0.44$ & $28.2 \pm 0.17$ \\
\hline 3. & $\mathrm{DO}(\mathrm{ml} / \mathrm{L})$ & $6.12^{\mathrm{b}} \pm 0.02$ & $6.03^{\mathrm{b}} \pm 0.04$ & $5.72^{\mathrm{a}} \pm 0.17$ & $5.52^{\mathrm{a}} \pm 0.06$ \\
\hline 4. & $\begin{array}{l}\text { Water hardness } \\
\left(\mathrm{CaCO}_{3} / \mathrm{L}\right)\end{array}$ & $143.17^{\mathrm{c}} \pm 0.44$ & $136.03^{\mathrm{a}} \pm 0.29$ & $138.83^{\mathrm{b}} \pm 1.42$ & $135.17^{\mathrm{a}} \pm 0.17$ \\
\hline 5. & Alkalinity $(\mathrm{mg} / \mathrm{L})$ & $147.50^{\mathrm{a}} \pm 0.29$ & $155.50^{c} \pm 0.28$ & $151.33^{\mathrm{c}} \pm 0.28$ & $155.33^{\mathrm{a}} \pm 0.60$ \\
\hline 6. & $\begin{array}{l}\text { Ammonia } \\
\left(\mu \mathrm{g} \cdot \mathrm{at} . \mathrm{NH}_{3} \cdot \mathrm{N} / \mathrm{L}\right)\end{array}$ & $0.058^{\mathrm{a}} \pm 0.002$ & $0.075^{\mathrm{b}} \pm 0.002$ & $0.087^{\mathrm{c}} \pm 0.001$ & $0.093^{\mathrm{d}} \pm 0.02$ \\
\hline 7. & $\begin{array}{l}\text { Nitrite } \\
\left(\mu \text { g.at. } \mathrm{NO}_{2} \mathrm{~N} / \mathrm{L}\right)\end{array}$ & $15.25^{\mathrm{a}} \pm 0.03$ & $16.21^{\mathrm{b}} \pm 0.05$ & $18.43^{c} \pm 0.03$ & $18.36^{\mathrm{c}} \pm 0.19$ \\
\hline 8. & $\begin{array}{l}\text { Nitrate } \\
\left(\mu \text { g.at.NO } \mathrm{NO}_{3} \mathrm{~N} / \mathrm{L}\right)\end{array}$ & $0.85 b^{c} \pm 0.03$ & $0.92^{c} \pm 0.01$ & $0.75^{\mathrm{a}} \pm 0.03$ & $0.78^{\mathrm{ab}} \pm 0.01$ \\
\hline 9. & $\begin{array}{l}\text { Phosphate } \\
\left.\text { ( } \mu \text { g.at.PO } \mathrm{PO}_{4} \mathrm{P} / \mathrm{L}\right)\end{array}$ & $25.59^{\mathrm{a}} \pm 0.35$ & $27.51^{\mathrm{b}} \pm 0.04$ & $29.78^{c} \pm 0.04$ & $36.11^{\mathrm{d}} \pm 0.06$ \\
\hline
\end{tabular}

Each value is the mean of three observations. Mean bearing at least one common superscript within a row do not differ significantly $(\mathrm{P}<0.05)$ 
Table.2 Haemoglobin content (g/dl ) of tilapia fed with fucoidan incorporated and control diet

\begin{tabular}{|c|c|c|c|c|}
\hline $\begin{array}{c}\text { Duration } \\
\text { (Days) }\end{array}$ & $\begin{array}{c}\text { Control } \\
\text { (g/dl) }\end{array}$ & $\begin{array}{c}\text { Fucoidan supplemented } \\
\text { with 0.1\% (g/dl) }\end{array}$ & $\begin{array}{c}\text { Fucoidan supplemented } \\
\text { with 0.2\% (g/dl) }\end{array}$ & $\begin{array}{c}\text { Fucoidan supplemented } \\
\text { with 0.3\% (g/dl) }\end{array}$ \\
\hline $\begin{array}{r}\text { P. tetrastromatica } \\
\text { Initial }\end{array}$ & $5.07 \pm 0.03$ & $5.07 \pm 0.03$ & & \\
\hline $\mathbf{1 5}$ & $5.09 \pm 0.01$ & $5.12 \pm 0.02$ & $5.06 \pm 0.02$ & $5.06 \pm 0.01$ \\
\hline $\mathbf{3 0}$ & $5.20 \pm 0.05$ & $5.31 \pm 0.06$ & $5.07 \pm 0.03$ & $5.20 \pm 0.05$ \\
\hline $\mathbf{4 5}$ & $5.38 \pm 0.05$ & $5.72 \pm 0.06$ & $5.13 \pm 0.15$ & $5.80 \pm 0.19$ \\
\hline $\mathbf{6 0}$ & $5.59 \pm 0.13$ & $5.61 \pm 0.03$ & $5.77 \pm 0.08$ & $5.74 \pm 0.07$ \\
\hline S. oligocystum & & & $5.69 \pm 0.13$ & $5.67 \pm 0.02$ \\
\hline $\mathbf{1 5}$ & $5.13 \pm 0.04$ & $5.14 \pm 0.03$ & & $5.18 \pm 0.07$ \\
\hline $\mathbf{3 0}$ & $5.16 \pm 0.02$ & $5.22 \pm 0.04$ & $5.09 \pm 0.03$ & $5.43 \pm 0.05$ \\
\hline $\mathbf{4 5}$ & $5.41 \pm 0.11$ & $5.39 \pm 0.08$ & $5.19 \pm 0.01$ & $5.54 \pm 0.04$ \\
\hline $\mathbf{6 0}$ & $5.54 \pm 0.06$ & $5.62 \pm 0.11$ & $5.32 \pm 0.06$ & $5.69 \pm 0.12$ \\
\hline
\end{tabular}

Table.3 WBC count of tilapia fed with fucoidan incorporated and control diet

\begin{tabular}{|c|c|c|c|c|}
\hline $\begin{array}{c}\text { Duration } \\
\text { (Days) }\end{array}$ & $\begin{array}{c}\text { Control } \\
\left(\mu \mathrm{I}^{-1}\right)\end{array}$ & $\begin{array}{c}\text { 0.1\% fucoidan } \\
\left(\mu \mathrm{l}^{-1}\right)\end{array}$ & $\begin{array}{c}0.2 \% \text { fucoidan } \\
\left(\mu \mathrm{I}^{-1}\right)\end{array}$ & $\begin{array}{c}0.3 \% \text { fucoidan } \\
\left(\mu \mathrm{l}^{-1}\right)\end{array}$ \\
\hline \multicolumn{5}{|c|}{ P. tetrastromatica } \\
\hline Initial & $2988 \pm 21$ & $2986 \pm 14$ & $2992 \pm 21$ & $2995 \pm 16$ \\
\hline 15 & $3146 \pm 41$ & $3145 \pm 24$ & $3255 \pm 27$ & $3331 \pm 18$ \\
\hline 30 & $3250 \pm 29$ & $3353 \pm 20$ & $3405 \pm 10$ & $3881 \pm 17$ \\
\hline 45 & $3301 \pm 13$ & $3493 \pm 23$ & $3508 \pm 17$ & $3790 \pm 15$ \\
\hline 60 & $3308 \pm 22$ & $3573 \pm 23$ & $3580 \pm 15$ & $3817 \pm 33$ \\
\hline \multicolumn{5}{|c|}{ S. oligocystum } \\
\hline 15 & $2833 \pm 14$ & $2830 \pm 15$ & $3100 \pm 29$ & $3217 \pm 90$ \\
\hline 30 & $3043 \pm 23$ & $3173 \pm 15$ & $3433 \pm 20$ & $3803 \pm 23$ \\
\hline 45 & $3116 \pm 18$ & $3273 \pm 21$ & $3557 \pm 23$ & $3543 \pm 24$ \\
\hline 60 & $3313 \pm 90$ & $3443 \pm 18$ & $3383 \pm 90$ & $3453 \pm 36$ \\
\hline
\end{tabular}

Each value is the mean of three observations. Mean bearing at least one common superscript within a row do not differ significantly $(\mathrm{P}<0.05)$

Table.4 RBC count of tilapia fed with fucoidan incorporated and control diet

\begin{tabular}{|c|c|c|c|c|}
\hline $\begin{array}{c}\text { Duration } \\
\text { (Days) }\end{array}$ & $\begin{array}{c}\text { Control } \\
\left({\mathrm{x} 10^{6}}^{6} \mathrm{I}^{-1}\right)\end{array}$ & $\begin{array}{l}0.1 \% \text { fucoidan } \\
\left(\times 10^{6} \mu \mathrm{I}^{-1}\right)\end{array}$ & $\begin{array}{l}0.2 \% \text { fucoidan } \\
\left(\mathrm{x}^{6} \mathrm{C}^{6} \mu \mathrm{l}^{-1}\right)\end{array}$ & $\begin{array}{l}0.3 \% \text { fucoidan } \\
\left(\mathrm{x}^{6} \mathrm{C}^{6} \mu \mathrm{l}^{-1}\right)\end{array}$ \\
\hline \multicolumn{5}{|c|}{ P. tetrastromatica } \\
\hline Initial & $2.66 \pm 0.03$ & $2.66 \pm 0.04$ & $2.67 \pm 0.04$ & $2.64 \pm 0.03$ \\
\hline 15 & $2.63 \pm 0.04$ & $2.75 \pm 0.13$ & $2.73 \pm 0.09$ & $2.87 \pm 0.03$ \\
\hline 30 & $2.70 \pm 0.07$ & $2.84 \pm 0.11$ & $2.87 \pm 0.03$ & $2.71 \pm 0.08$ \\
\hline $45^{\prime}$ & $2.46 \pm 0.23$ & $2.78 \pm 0.04$ & $2.66 \pm 0.08$ & $2.67 \pm 0.07$ \\
\hline 60 & $2.76 \pm 0.12$ & $2.75 \pm 0.08$ & $2.78 \pm 0.06$ & $2.86 \pm 0.02$ \\
\hline \multicolumn{5}{|c|}{ S.oligocystum } \\
\hline 15 & $2.74 \pm 0.07$ & $2.66 \pm 0.13$ & $2.72 \pm 0.12$ & $2.68 \pm 0.11$ \\
\hline 30 & $2.54 \pm 0.063$ & $2.58 \pm 0.10$ & $2.69 \pm 0.07$ & $2.74 \pm 0.12$ \\
\hline 45 & $2.71 \pm 0.05$ & $2.61 \pm 0.15$ & $2.64 \pm 0.04$ & $2.69 \pm 0.09$ \\
\hline 60 & $2.70 \pm 0.15$ & $2.54 \pm 0.13$ & $2.59 \pm 0.08$ & $2.71 \pm 0.08$ \\
\hline
\end{tabular}


Table.5 Mortality and Relative Percentage Survival (RPS )of fish Oreochromis mossambicus fed on different concentrations of fucoidan ( $P$. tetrastromatica $)$ supplemented diets after challenged with Aeromonas hydrophilain 60 days

\begin{tabular}{|c|c|c|c|c|}
\hline Concentration & $\begin{array}{c}\text { No. of } \\
\text { challenged } \\
\text { Fish }\end{array}$ & $\begin{array}{c}\text { No. of } \\
\text { Mortalities }\end{array}$ & $\begin{array}{c}\text { Survival } \\
(\%)\end{array}$ & $\begin{array}{c}\text { Relative Percentage } \\
\text { Survival }\end{array}$ \\
\hline $\mathbf{0 . 1 \%}$ fucoida & 20 & $7(35)$ & 65 & 47 \\
\hline $\mathbf{0 . 2 \%}$ fucoidan & 20 & $5(25)$ & 75 & 62 \\
\hline $\mathbf{0 . 3 \%}$ fucoidan & 20 & $4(20)$ & 80 & 70 \\
\hline Control & 20 & $13(65)$ & 35 & - \\
\hline
\end{tabular}

Table.6 Mortality and Relative Percentage Survival (RPS )of fish Oreochromis mossambicus fed on different concentrations of fucoidan (S. oligocystum )supplemented diets after challenged with Aeromonas hydrophilain 60 days

\begin{tabular}{|c|c|c|c|c|}
\hline Concentration & $\begin{array}{c}\text { No. of challenged } \\
\text { Fish }\end{array}$ & $\begin{array}{c}\text { No. of } \\
\text { Mortalities }\end{array}$ & $\begin{array}{c}\text { Survival } \\
(\mathbf{\%})\end{array}$ & $\begin{array}{c}\text { Relative Percentage } \\
\text { Survival }\end{array}$ \\
\hline $\mathbf{0 . 1 \%}$ fucoidan & 20 & $10(50)$ & 50 & 24 \\
\hline $\mathbf{0 . 2 \%}$ fucoidan & 20 & $7(35)$ & 65 & 47 \\
\hline $\mathbf{0 . 3 \%}$ fucoidan & 20 & $6(30)$ & 70 & 54 \\
\hline Control & 20 & $13(65)$ & 35 & - \\
\hline
\end{tabular}

Fish were challenged by intramuscular injection with A. hydrophila strain. Relative percent survival=1-[\% mortality in the vaccinated group/ \% mortality in the control group] x 100. RPS values over 50 indicate positive effect of the vaccine (Amend, 1981)

Fig.1 NBT reduction in tilapia fed with $P$. tetrastromatica fucoidan incorporated diet and control

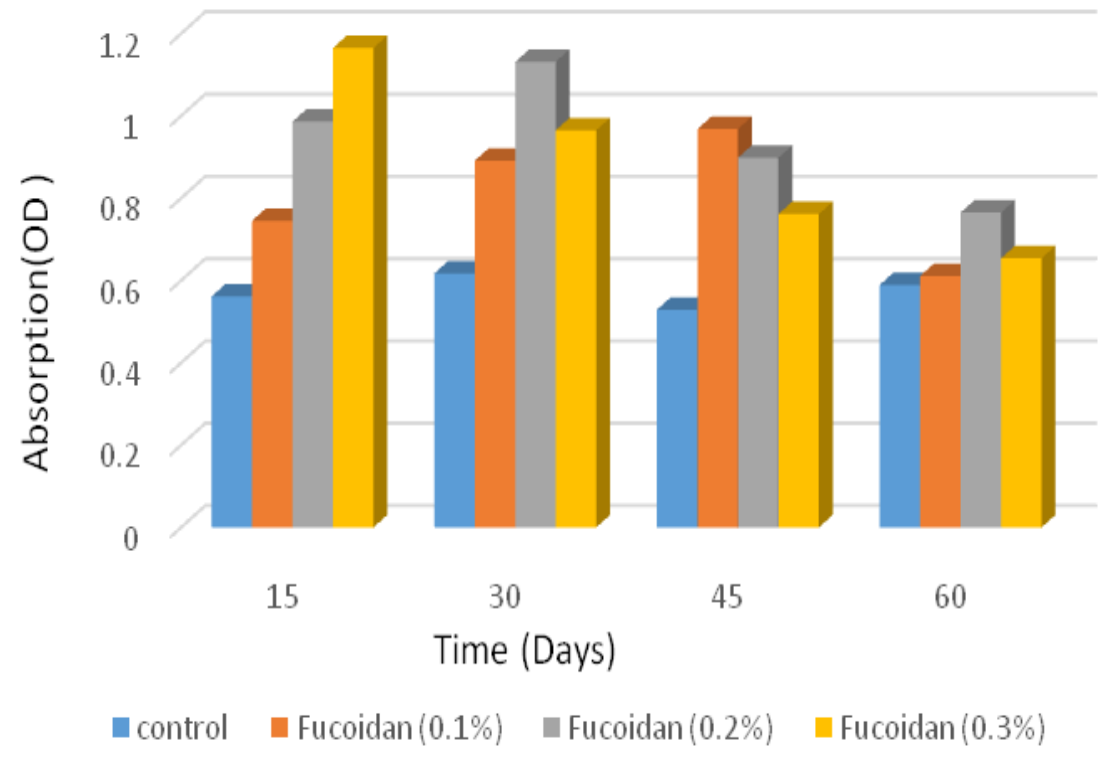


Fig.2 NBT reduction in tilapia fed with S. oligocystum fucoidan incorporated diet and control

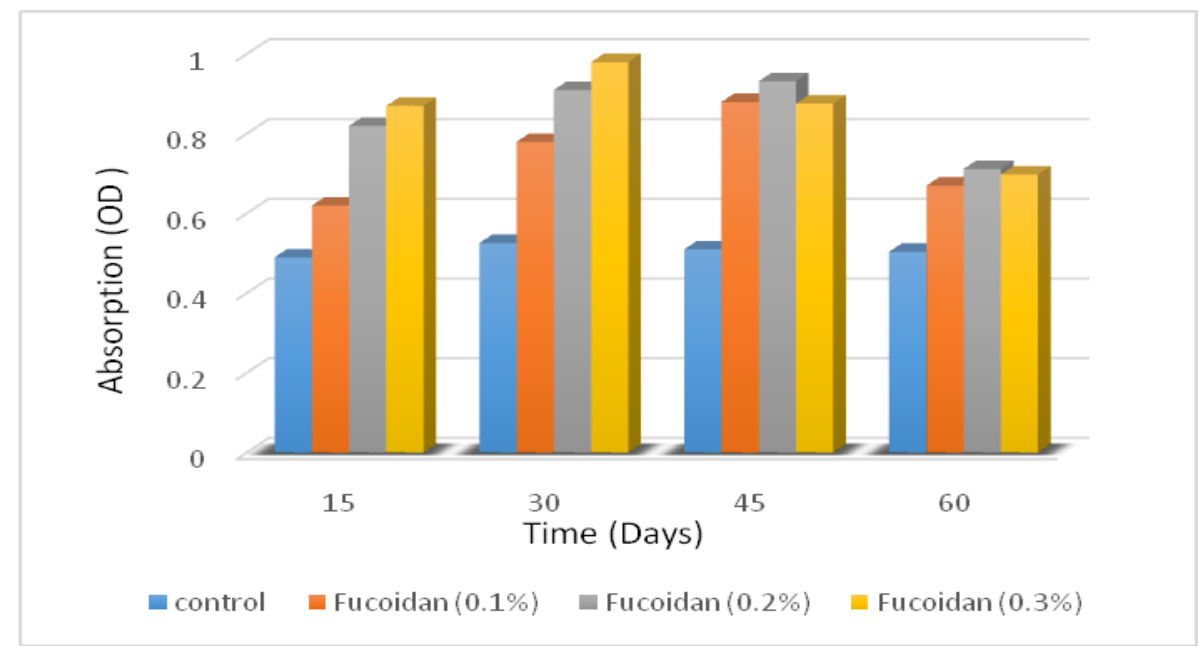

Fig.3 Lysozyme activity of tilapia supplemented with fucoidan of P. tetrastromatica

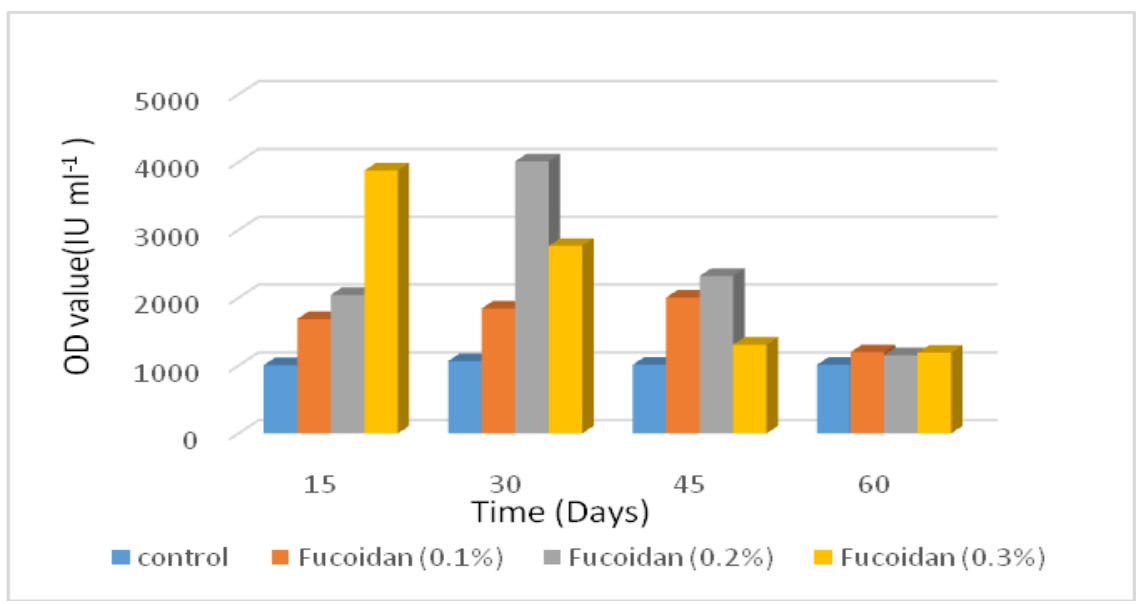

Fig.4 Lysozyme activity of Tilapia supplemented with fucoidan of S. oligocystum

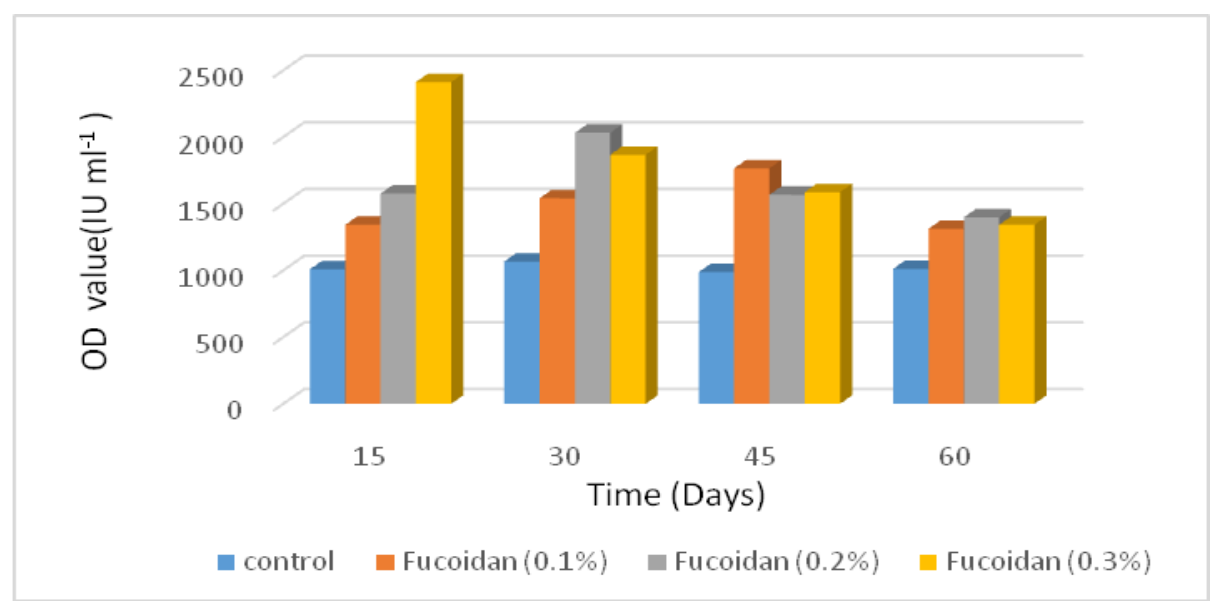


The results of fucoidan extracts from $P$. tetrastromatica and S. oligocystum indicated that there was no significant variation in control and fucoidan supplemented diets at three concentrations and control group in $\mathrm{Hb}$ and RBC content. However, White blood cells (WBCs) of fish play a crucial role in the cellular immunity and resistance to infectious diseases (Whyte 2007). In the present study, WBC count was found to be significantly increased in tilapia fed with fucoidan from $P$. tetrastromatica. This result corroborates with Yang et al., 2014 who studied the effect of dietary fucoidan on the blood constituents, anti-oxidative and innate immunity in juvenile cat fish Pleteobagrus fulvidraco and reported that dietary fucoidan had no significant effects on the WBC, RBC, hemoglobin of the yellow cat fish. However, oral administration of fucoidan at an optimal level decreased the serum parameters such as serum total protein, total cholesterol, glucose and triglyceride and improved the anti- oxidation and innate immunity of the treated fish. Similar result observed in fish Nile tilapia was fed with dietary supplementation of CloSTAT, black cumin, or combination of the two enhanced the overall immune response due significant increase of the WBC numbers, globulin proteins and the phagocytic activities of fish phagocytes (Elkamel and Mosaad 2012). Thus, the fucoidan extracts from $P$. tetrastromatica and $S$. oligocystum did not bring about significant variation in $\mathrm{Hb}$ and RBC counts of tilapia when added with the diet, but had caused some increase in WBC counts.

As fish depends mainly on innate immunity for protection against disease, attention was given in this study to assess the innate immune response with respect to fucoidan incorporated diet. Many studies have earlier demonstrated that different types of polysaccharides could improve the immunity and antioxidant capacity of cultured fish
(Smit 2004; Hwang et al., 2010; Yeh et al., 2006; Immanuel et al., 2012). In the present investigation, tilapia fed with fucoidan incorporated diet, the NBT reduction increased with increasing concentration of fucoidan obtained from $P$. tetrastromatica and $S$. oligocystum after 15 days upto 30 days. However, there was drastic reduction in NBT assays.

Phagocytosis is a primary, non-specific defense mechanism against invasion of pathogenic organisms of hosts. The NBT assay is a quick inexpensive test focusing on the ability of phagocytes to induce the dye by the production of oxygen radicals in macrophages, and a very good indicator of health status or their immunization effectiveness in fish (Anderson 1992). In mammals, the oxygen radicals are aimed at the destruction of bacterial invaders.

The ability of macrophages to kill pathogenic microbes is probably one of the most important mechanisms of protection against disease among fishes. It has been reported that an increased phagocytic activity in shrimps fed with fucoidan $(200 \mathrm{mg} / \mathrm{kg}$ of body weight, group 12-15g) was achieved when compared to the control group due to the immunostimulatary activity of fucoidan (Immanuel et al., 2012). Fucoidan would have stimulated the immuno system in several ways and most of them are related to their ability to modify cell surface properties (Usov et al., 2001). Oral intake of the fucoidan derived from dietary brown seaweed had inhibited the protective effects through direct inhibition of viral replication and stimulation of the immune system (innate and adaptive) function (Hayashi et al., 2008). Sargassum thunbergii and $S$. kjellmaniaun were also reported to possess antitumor activity, which is related to the enhancement of immune responses according to Itohet al., 1993. 
Lysozyme is a cationic enzyme that breaks $\beta$ 1, 4 glycosidic bonds between $\mathrm{N}$-acetyl glucosamine in the peptidoglycan of bacterial cell walls. This action is known to attack mainly Gram positive bacteria as well as some Gram negative bacteria in conjunction with complement (Alexander amd Ingram 1992).

A lysozyme activity unit was defined as the amount of enzyme inquired to decrease the absorbance at a rate of $0.001 / \mathrm{min} / \mathrm{ml}$. Cyprinus carpio fed with chitosan $(1 \%$ )and levamisole $\left(250 \mathrm{mg} \mathrm{kg}^{-1}\right.$ of diet )enhanced the serum lysozyme activity in the beginning which later declined after 60 days of culture operation in ponds (Gopalakannan and Arul 2006).

The lysozyme activity of control and experimental group fishes fed with fucoidan from $P$. tetrastromatica showed significant variation in the present study. Fucoidan activates the macrophages which in turn increases lysozyme activity (Yang et al., 2008). The leaf extract of Ocimum sanctum fed at the rate of $20 \mathrm{mg} / \mathrm{kg}$ fed for a single day was found to be optimal for enhancing phagocytic and NBT reduction in tilapia (Logambal et al., 2000). Although research findings on the effect of fucoidan on immunological parameters in shrimp and rats are available, similar reports in fish is very scarce.

The serum lysozyme activities of the yellow catfish fed with fucoidan from Sargassum spp was found to be significantly higher than the control and they have opined that fucoidan significantly influences the blood characteristics, antioxidant status and nonspecific immune responses in juvenile yellow catfish (Yang et al., 2014).

The observed variations in the levels of different immune related parameters assessed in this study at different concentrations of fucoidan fed incorporated diet in tilapia at various time intervals have indicated that the dosages and timing followed for administration plays an important role as reported by Sakai (1999). Immune modulating substances have the ability to increase immune function, when it is depressed, and also to reduce it, when it is over-stimulated (Kuznetsova et al., 2003). Fucoidan may provide an abundant supply of fucose, one of the necessary saccharides, and smaller amounts of several other required sugars. This is likely to be one mechanism by which the fucoidan exert their immunomodulatory effect. Determination of the exact level of incorporation required for optimal immune responsiveness is very helpful for feed formulation as fucoidan is not cheap and the feed cost will increase at higher incorporation level. However, the active principle compound responsible for the immunostimulatory property observed in the present study has to be identified.

The reduction in mortality of all the test groups in challenge experiments had increased with the increasing concentrations of fucoidan, which could be due to the enhancement of the non-specific immune system of the fish. There is strong experimental evidence that oral administration of fucoidan from brown seaweeds viz., S. wightii and S. polycystum reduced the impact of the WSSV infection in P. monodon (Chotigeat et al., 2004; Choi et al., 2005; Immanuel et al., 2012; Kanimozhi et al., 2013).

Fucoidan is a heteropolysaccharide and is mainly composed of fucose, sulphate, uronic acid, and small quantities of monosaccharides. The composition may vary between species and the extraction techniques used to extract the fucoidan which will have a large impact on the determination of the final 
structure of fucoidan (Chizhov et al., 1999; Duarte et al., 2001; Bilan et al., 2002).

Fucoidan thus possess an immunostimulating effect in tilapia, O. mossambicus, under optimal concentration of fucoidan based on the species and its composition. In the present study, it is observed that fucoidan derived from $S$. oligocystum has relatively lower lysozyme and NBT activity than $P$. tetrastromatica but higher than the control. This could be due to difference of molecular structure, relative molecular mass, polysaccharide compositions in particular degree of sulphate content between the species of $P$. tetrastromatica and $S$. oligocystum.

The results specified that fishes fed with fucoidan extracted from $P$. tetrastromatica and $S$. oligocystum invariably reduce the mortality than the control and significantly enhance the relative percentage survival when challenged with Aeromonas hydrophila. However, the detailed mechanism of action of the fucoidan to inhibit pathogens or improve immunity need to be investigated more thoroughly.

In conclusion based on the results of the study, it is evident that $0.2 \%, 0.3 \%$ of fucoidan from $P$. tetrastromatica and $0.3 \%$ fucoidan from $S$. oligocystum certainly enhance the non-specific immunity of tilapia $O$. mossambicus which may be considered to improve the immune status of the fish. Thus, it can be concluded that fucoidan could be used as immunostimulant for the fish, $O$. mossambicus as it can improve its resistance to disease causing pathogen.

\section{Acknowledgements}

The financial assistance from Tamilnadu Veterinary and Animal Sciences University, Chennai is gratefully acknowledged.

\section{References}

Alexander, JB., Ingram, GA. 1992. Noncellular nonspecific defence mechanisms of fish. Annual Review of Fish Diseases 2:249-279.

Amend, DF. 1981. Potency testing of fish vaccines In: Anderson DP and Hennessen $\mathrm{H}$ (Ed.), Fish Biologies: Serodiagnostics and vaccines developments in Biological standardization, 49, 447-454.

Anderson, DP. 1992. Immunostimulants, adjuvants, and vaccine carriers in fish: applications to aquaculture. Annual Review of Fish Diseases 2:281-307.

APHA (American Public Health Association). 1995. Standard method for the examination of water and waste water $\left(19^{\text {th }} \mathrm{Ed}\right)$, Washington, DC.

Barcellos, LJ., Kreutz, LC., de Souza, C., Rodrigues, LB., Fioreze, I., Quevedo, RM. 2004. Hematological changes in jundia (RhamdiaquelenQuoy and GaimardPimelodidae )after acute and chronic stress caused by usual aquacultural management, with emphasis on immunosuppressive effects. Aquaculture 237(1):229-236.

Bilan, MI., Grachev, AA., Ustuzhanina, NE., Shashkov, AS., Nifantiev, NE., Usov, AI. 2002. Structure of a fucoidan from the brown seaweed Fucus evanescens C. Ag. Carbohydrate research 337(8):719-730.

Chattopadhyay, N., Ghosh, T., Sinha, S., Chattopadhyay, K., Karmakar, P., Ray, B. 2010. Polysaccharides from Turbinaria conoides: Structural features and antioxidant capacity. Food Chemistry 118(3):823-829.

Chizhov, AO., Dell, A., Morris, HR., Haslam, SM., McDowell, RA., Shashkov, AS. 1999. A study of fucoidan from the brown seaweed Chorda filum. Carbohydrate Research 320(1):108-119.

Choi, EM., Kim, AJ., Kim, YO., Hwang, JK. 2005. Immunomodulating activity of arabinogalactan and fucoidan in vitro. Journal of medicinal food 8(4):446-453.

Chotigeat, W., Tongsupa, S., Supamataya, K., 
Phongdara, A. 2004. Effect of fucoidan on disease resistance of black tiger shrimp. Aquaculture 233(1):23-30.

Duarte, ME., Cardoso, MA., Noseda, MD., Cerezo, AS. 2001. Structural studies on fucoidans from the brown seaweed Sargassum stenophyllum. Carbohydrate Research 333(4):281-293.

Elkamel, A., Gamal, M. Mosaad. 2012. Immunomodulation of Nile Tilapia, Oreochromis niloticus, by Nigella sativa and Bacillus subtilis. Journal of Aquaculture Research and development 3:6.

Gopalakannan, A., Arul, V. 2006. Immunomodulatory effects of dietary intake of chitin, chitosan and levamisole on the immune system of Cyprinus carpio and control of Aeromonas hydrophila infection in ponds. Aquaculture 255(1):179-87.

Hayashi, L., Yokoya, NS., Ostini, S., Pereira, RT., Braga, ES., Oliveira, EC. 2008. Nutrients removed by Kappaphycus alvarezii (Rhodophyta, Solieriaceae )in integrated cultivation with fishes in recirculating water. Aquaculture 277(3):18591.

Hwang, PA., Wu, CH., Gau, SY., Chien, SY., Hwang, DF. 2010. Antioxidant and immune-stimulating activities of hot-water extract from seaweed Sargassum hemiphyllum. Journal of Marine Science and Technology 18(1):41-46.

Immanuel, G., Sivagnanavelmurugan, M., Marudhupandi, T., Radhakrishnan, S., Palavesam, A. 2012. The effect of fucoidan from brown seaweed Sargassum wightii on WSSV resistance and immune activity in shrimp Penaeus monodon (Fab). Fish \& shellfish immunology 32(4):551-564.

Itoh, H., Noda, H., Amano, H., Zhuaug, C., Mizuno, T., Ito, H. 1993. Antitumor activity and immunological properties of marine algal polysaccharides, especially fucoidan, prepared from Sargassum thunbergii of Phaeophyceae. Anticancer research 13(6A):2045-52.

Kanimozhi, S., Krishnaveni, M., Deivasigmani, B., Rajasekar, T., Priyadarshni, P. 2013.
Immunomostimulation effects of Sargassum whitti on Mugil cephalus against Pseudomonas fluorescence. International Journal of Current Microbiology and Applied Sciences 2(7):93-103.

Kannan, L., Krishnamurthy, K. 1978. A survey of the algae of the Porto-Novo region (Coromandel Coast. Bay of Bengal). Seaweed Research and Utilization 5(1\&2):1-4.

Karunasagar, I., Rosalind, G. 1991. Immunological response of the Indian major carps to Aeromonas hydrophila vaccine. Journal of Fish Disease 14(3):413-417.

Kuznetsova, TA., Zaporozhets, TS., Besednova, NN., Shevchenko, NM., Zviagintseva, TN., Mamaev, AN. 2003. Immunostimulating and anticoagulating activity of fucoidan from brown algae Fucus evanescens of Okhotskoe sea. Antibiotik iikhimioterapiia $=$ Antibiotics and chemoterapy [sic], 48(4):11-3.

Lee, NY., Ermakova, SP., Choi, HK., Kusaykin, MI., Shevchenko, NM., Zvyagintseva, TN. 2008. Fucoidan from Laminaria cichorioides inhibits AP- 1 transactivation and cell transformation in the mouse epidermal JB6 cells. Molecular carcinogenesis 47(8):629-37.

Logambal, SM., Venkatalakshmi, S., Michael, RD. 2000. Immunostimulatory effect of leaf extract of Ocimum sanctum Linn. in Oreochromis mossambicus (Peters). Hydrobiologia 430(1-3):113-20.

Maheswaran, ML., Padmavathy, S., Gunalan, B. 2013. Screening and characterization of marine seaweeds and its antimicrobial potential against fish pathogens. International Journal of Fisheries and Aquatic Studies 1:1-13.

Mantri, VA., Eswaran, K., Shanmugam, M., Ganesan, M., Veeragurunathan, V., Thiruppathi, S. 2017. An appraisal on commercial farming of Kappaphycus alvarezii in India: success in diversification of livelihood and prospects. Journal of Applied Phycology 29(1):335-57. 
Oza, RM., Zaidi, SH. 2000. A Revised Checklist of Indian Marine Algae, Central Salt and Marine Chemicals Research Institute, Bhavanagar, India. pp 296.

Parry, Jr RM., Chandan, RC., Shahani, KM. 1965. A Rapid and Sensitive Assay of Muramidase. Proceedings of the Society for Experimental Biology and Medicine 119(2):384-386.

Radhika, D., Veerabahu, C., Priya, R. 2012. Antibacterial activity of some selected seaweeds from the Gulf of Mannar coast, South India. Asian journal of pharmaceutical and clinical research 5(4):89-90.

Rani, V., Jawahar, P., JeyaShakila, R. 2015. Seasonal variation in biomass and distribution of brown seaweeds (Phaeophyceae) in Gulf of Mannar, Tamilnadu, India. The Bioscan 10(3): 11231129.

Rao, UM. 1972. Ecological observations of some intertidal algae of Mandapam coast. Proceedings of the Indian National Science Academy 5(3\&4):298-307.

Sakai, M. 1999. Current research status of fish immunostimulants. Aquaculture 172(1):6392.

Seafood Plus. 2004. Retrived from www.seafoodplus.org / fileadmin / files / news / 2004-0122SFRTD1 launch Brussels.pdf. Accessed 25.03.10

Smit, AJ. 2004. Medicinal and pharmaceutical uses of seaweed natural products: a review. Journal of applied phycology 16(4):245-62.

Stasiak, SA., Baumann, PC. 1996. Neutrophil activity as a potential bioindicator for contaminant analysis. Fish \& Shellfish Immunology 6(7):537-539.
Usov, AI., Smirnova, GP., Klochkova, NG. 2001. Polysaccharides of algae: 55. Polysaccharide composition of several brown algae from Kamchatka. Russian Journal of Bioorganic Chemistry 27(6):395-399.

Whyte, SK. 2007. The innate immune response of finfish - a review of current knowledge. Fish Shellfish Immunology 23:1127-1151

Yang, C., Chung, D., You, S. 2008. Determination of physicochemical properties of sulphated fucans from sporophyll of Undaria pinnatifida using light scattering technique. Food Chemistry 111(2):503-507.

Yang, Q., Yang, R., Li, M., Zhou, Q., Liang, X., Elmada, ZC. 2014. Effects of dietary fucoidan on the blood constituents, antioxidation and innate immunity of juvenile yellow catfish (Pelteobagrus fulvidraco). Fish \& shellfish immunology 41(2):264270.

Yeh, SP., Chang, CA., Chang, CY., Liu, CH., Cheng, W. 2008. Dietary sodium alginate administration affects the fingerlings growth and resistance to Streptococcus sp. and iridovirus and juvenile nonspecific immune responses of the orange spotted grouper, Epinephelus coicoides. Fish and Shellfish Immunology 25:19-27.

Yeh, ST., Lee, CS., Chen, JC. 2006. Administration of hot-water extract of brown seaweed Sargassumduplicatum via immersion and injection enhances the immune resistance of white shrimp Litopenaeus vannamei. Fish \& shellfish immunology 20(3):332-345.

\section{How to cite this article:}

Rani, V., P. Jawahar, R. Jeyashakila and Srinivasan, A. 2020. Effect of Fucoidan of Brown Seaweeds on the Immuno-haematological Change and the Disease Resistance against Aeromonas hydrophila in Tilapia Oreochromis mossambicus. Int.J.Curr.Microbiol.App.Sci. 9(08): 636-649. doi: https://doi.org/10.20546/ijcmas.2020.908.071 